\title{
Untaping the potential of strategic partnerships with the stakeholders in museums - a managerial approach
}

\author{
Cosmin ILIE \\ "Dunarea de Jos" University of Galati, Romania \\ cosmin_ilie2005@yahoo.com
}

\begin{abstract}
The strong emphasis on achieving excellence in the services the museums provide to its target public opens a new road to an area that is not characteristic of traditional museology, namely the journey of innovation. This road to innovation has two pillars: a mature knowledge-based strategy (in response to identified needs of target groups) and the ability to provide education (according to identified needs). Both components are totally dependent on visitors, their needs and their personal or collective experiences. This paper addresses these pillars, considering that education is not a mere accumulation of knowledge, but how the visitor experiences, interacts and learns during his visit. Using the literature review as research methodology, this paper aims to analyze the stakeholders of a museum and to assess their partnerships with other museums, by highlighting the clear advantages of stakeholder involvement in the management system of the museum. The main results shows that museums, as cultural organizations, are a brick at the foundation of economic development in many cities. The involvement and support of the stakeholders is essential for a museum that wants to set and meet appropriate community service goals. Understanding stakeholder's value is important for effective reporting on the performance of the museum, which transforms and translates through continuous public support for the museum.
\end{abstract}

Keywords: museum, management, stakeholders, visitor experience, community responsibility, social responsibility, cultural sustainability.

\section{Introduction}

In a century of changes, of speed, of demands for any product from the free market, the museum of the $21^{\text {st }}$ century strives to meet the needs of the visitors and communities of which it is part, while remaining true to the fundamental and traditional values.

The strong emphasis on achieving excellence in the services the museum offers to its diverse audiences opens a new road to an area that is not characteristic of traditional museology, namely the road to innovation (content, organization, preservation techniques, presentation techniques and in ways of transmitting and presenting information).

The road to innovation has two main components: a mature strategy (in response to the identified needs of the target groups) and the ability to provide education (according to identified needs). "In a turbulent environment and continuous struggle for achieving a competitive advantage, strategic thinking and planning implies different approaches" (Bratianu, C. \& Bolisani, E.. 2015, 169). Both components are totally dependent on visitors, their needs and their personal or collective experiences, and the museum must take into account that education is not a mere accumulation of knowledge, but how the visitor experiences, interacts and learns during his visit.

Decision-makers, as well as all museum staff, must place the visitor in the center of attention, services and museum resources. In addition a museum provides physical, intellectual, and social facilities for visitors in order to enjoy an instructive, pleasant and comfortable visit to the museum.

The principles underpinning the provision of visitor quality services, according to Boylan and Woollard(2004), are: Human Rights and Equal Opportunities; open consultation 
and strategic partnerships with all stakeholders; an integrated policy and strategy that has the objective to serve the visitor; the quality of the visitor experience (real, potential or virtual) as the professional responsibility of all staff.

The present paper aims to analyze the stakeholders of a museum and their partnerships; its primary goal is to highlight the clear advantages of stakeholder involvement in museum management and to identify the current position in its cultural market.

What a museum is, what role does it have, the main features of museum's management, public relations, funding arrangements of a museum, and the principles of effective stakeholder`s management within a museum are information from which we will start in our approach to have a clearer picture of this research.

\section{Theoretical background}

The museum is a non-profit organization that produces products (exhibitions, school projects, various educational activities, etc.). The cost of products is only partly supported by customers / consumers (visitor audience), museum funding being often a form of subsidy from the authorities they are operating in. Museum subsidies are part of the national cultural policy of the state they are part of (Museums Association in the Netherlands), but it is not compulsory, as there are private museums with exclusive funding.

The main products: permanent exhibition and temporary exhibitions are ways to materialize and communicate the message of the organization.

The museum has various roles, and their fulfillment depends on how it manages to provide specific products / services to the public for each category.

The services provided by a museum are diverse, some of which are related to the cultural patrimony the museum manages, and others do not. Zbuchea(2005) gives some examples of services: exhibitions, guidance, educational programs, documentation, cultural entertaining services and ancillary services.

Most of the museums are at the service of the citizens and, to be successful, they have the duty to reflect that precisely through everything they do. Every organization has a mission of public interest, and museums are no exception as custodians of the cultural, natural and scientific heritage of a nation, a region and its people.

Depending on the country and the museum tradition of the place, there are various types of management: in some organizations the decision-making power is concentrated in the hands of a CEO and in others management is an important part of the tasks and responsibilities of the personnel specialized majority (ICOM - International Council of Museums). In both cases, it is very important for all those with managerial responsibilities to know the systems and administrative and legal rules applicable to the functions they perform, as well as the provisions of the laws and regulations under which they operate.

Nowadays, museums require a new managerial conception to restructure the traditional museum functions, in the light of the requirements of today's society, international competition, ever-increasing demands of the museum public, scientific, educational, cultural, recreational, divertissement and entertainment. It is necessary to adopt a new and modern concept of a live, interactive museum that integrates the museumschool, the museum-cultural center, the museum of the amphitheater, the museumuniversity, the museum of the traditional values, The "olympiad-school museum", the 
"folklore museum", the "cinematic museum". The museum represents a whole universe and must acquire the quality of being a multifaceted cultural center (Bucur, 2006).

From the scientific point of view, the most comprehensive definition is given by ICOM: the museum is a permanent, non-profit institution serving the society and its development, open to the public and conducting research on material testimonies related to man and the environment it acquires, preserves them and, most importantly, expounds them for study, education and enjoyment (Museums Association in the Netherlands, 2010).

From an administrative point of view, the museum, as a space for the social interaction of community members, is a permanent institution - an enterprise that manages a collection of objects, collections and organizes activities for a wide audience (Museums Association in the Netherlands, 2010).

Contemporary museums are moving institutions, cultural and communication centers, and interactive educational and entertainment venues. Traditional conservation and patrimony functions seem to be shadowed by new approaches, such as engagement education or socio-cultural forums (Zbuchea, 2010).

\section{Innovation in museums - a strategic management approach}

Innovation has become the key to adapting museums to the major changes that have taken place in recent decades in the environment in which such organizations operate.

In times of rapid change, the ability to implement innovation is the key source for adaptability of organizations (Vicente et al., 2012). The museum industry is an example of how much struggle and effort requires innovation, as an adaptation to a changing environment. The large number of new museums and their diversity, coupled with the growth of the leisure industry, forced the museums to compete with each other, as well as the leisure industry for a limited market. This new situation forced museums to focus on the visitor's needs and the development of new services and products.

In this context, innovation is the key to any organization, and for a museum is the essential requirement in the competition. Its implementation is a dynamic, nonlinear process, generated by a complex interaction of many factors.

A study conducted by Vicente et al. (2012) defines innovation in museums and cultural institutions as a tendency to incorporate new systems, technologies and processes that change both the way the museum works and how it exhibits visitor. In this respect, four aspects are proposed, through which innovation can be highlighted in museums:

a. technological innovations applied to management - related to improvements in museum management processes (digitized catalogs - archives, books, documents, photographs, etc.), software applications (for management and databases);

b. Technological innovations applied to the visitor experience - Try to increase the cultural services offered to visitors (virtual tours, virtual visits, interactive screens, photographic panels, scenography, web pages, web publications, etc.). Innovation has also been defined as the search for visitors through digital technologies and online access;

c. organizational innovation - is linked to changes in organizational structure and processes (application of managerial styles, characterized by a closer approach to the business model compared to the classic conservation and protection approach);

d. artistic innovation - can innovate through: content and form (a possibility to innovate in the content is to combine several forms of art). 
Strategic management helps the organization to weigh through certain dilemmas such as: reaching a large number of visitors, managing collections; accessibility versus security; a temporary exhibition of scientific research.

Strategic management distinguishes three main notions: the mission, goal and strategy of the museum that indicate to the organization what needs to be done in the future in order to occupy a healthy position in society, and the key word is choices (to accomplish the mission and achieve goals).

Developing an effective strategic management will help the museum become less dependent on the environment and be able to make its own choices, which must correspond to a constantly changing society.

As an institution, the main mission of the museum is education. The museum has to do the cultural and aesthetic education of the nation and must be able to demonstrate the identity of a national culture. According to the ideology of Alexandru Tzigara Samurcass, the founder of the Romanian Peasant Museum and the creator of a modern museum, the museum must be a temple and a school (Gheorghiu, 2013).

Much of the museum's mission has different requirements: educational, cultural, research and innovation in its specific field, in the classical sense of museology, and in modern theory adds aspects of tourism and entertainment (Zbuchea, 2005).

To achieve such a mission, it is necessary to attract a large number of visitors and their involvement in specific activities, each museum having a duty to know closely the behavior of its audience, what motivates and influences concrete actions.

The offer and the specific mission of a museum is materialized mainly through the permanent exhibition, but also through the temporal ones. The exhibitions have to fulfill two main conditions: to correspond to the mission, vision and values of the respective museum and to satisfy the needs, desires, curiosities of the visitors, as well as the specialists from the respective field and the related ones.

The characteristics of an exhibition should correspond to the vision of the museum`s role in the society`s life, but also be in line with the mentality of society in general. The exhibition always has an educational role and is a space of public discourse (Zbuchea, 2005).

In the Norwegian model studied by Mellemsether and Muller (2016), the notion of "new museology" represents a paradigm shift in museum theory and practice and offers a new perspective on the role the museum must have in society and a picture of the implementation of current requirements in the field: museums must interact with their audiences, provide individuals with qualitative experiences and be relevant and accessible to the communities they are part of; to contribute to the democratization of society and to adopt an inclusive practice, requirements that are closely related to their role as social institutions, thus achieving a shift from object-oriented institutions to people-centered institutions.

In this respect, the dialogue and involvement of the stakeholders inside and outside the organization are necessary to meet the obligations towards society.

Museums, as institutions, must respond to the requirements and act in accordance with stakeholder interests to ensure their support and legitimacy and to take sustainable action.

Stakeholders, defined as groups and actors influencing or depending on museum decisions, include owners, central and local authorities, sponsors, visitors / customers, the 
general public, donors, friends' associations, sponsors and service providers and assets used by the museum.

According to Lindquist (2012), stakeholder groups have a different impact on the total revenue of a museum. Public authorities (central and local) distributing financial support to museums base their decisions on political priorities, on the economic status of the public, on finance, and on competition with other areas of public resource policy. Visitors and customers are obviously vital to museums, and earnings generated by them are increasingly important to museum funding. Donors are important for museums, especially in the long run, but their behavior or preferences are difficult to predict, depending on many factors such as tax regulations, household income levels, and personal interests. Friends and volunteer associations are important resources and stakeholders for museums, generally working for promotion, for the benefit of museums. They contribute economically to museum budgets by collecting funds for various purchases, can arrange larger donations and actively promote the museum, with an important impact on visitor numbers and volunteer activities. However, these activities do not generate direct revenue for the museum. Founders, boards of directors and grant bodies are all major stakeholders for museums that contribute to museum funding.

The public (visitors in general) is a stakeholder group that only has an indirect economic impact on museums, but it is important for the legitimacy of museums and can react to behaviors that are perceived as illegitimate.

\section{Effective approach of museum stakeholders}

The term stakeholder was introduced in the economic language by Edward Freeman, in his work published in 1984 - Strategic Management: a Stakeholder Approach. Stakeholder, as defined by Freeman, defines any individual or group of individuals that may affect or be affected by the actions of an organization or by achieving its objectives.

Effective stakeholder management is very important, as there is no organization without stakeholders. Organizations need to have good relationships with their stakeholders, which can be divided by the criterion of importance into: mayors (investors, employees, visitors, customers); public (central and local authorities) and secondary (the rest of the persons directly or indirectly affected by the actions of the organization concerned).

The more stakeholders are satisfied, the more the museum will grow faster and safer on all levels and will achieve its goals more easily.

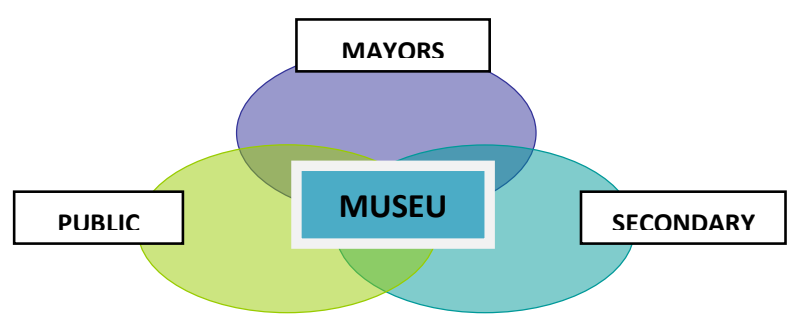

Figure 1. Main Stakeholders

Source: Author's own representation. 
In order for stakeholder management to be truly effective, a real, open and participative dialogue with all those in this category is needed, both active and vocal, as well as shy, passive, or simply not knowing that are part of this category.

The concept of stakeholder is "misleadingly simple" for Freeman (1984, p.246). It is "simple" because it is easy to identify those groups and individuals that can affect or are affected by the goal of an organization. It is "deceiving" because once stakeholders are identified, the task of managing relationships with them is enormous

For Wolfe and Putler (2002), the desired stakeholder management is aligning and complying corporate priorities and actions with the stakeholders' needs, which will lead to better cohesion between the organization and its environment, thus increasing the organization's likelihood of success.

The benefits of using stakeholder management come from the valuable information that it provides, information that helps to conceptualize, understand and analyze external media. It is a structure of knowledge that determines how a manager perceives, selects, evaluates and interprets the attributes of the environment.

The stakeholder's management supports the strategic objectives of an organization by: interpreting and influencing the internal and external environments; creating positive relationships with stakeholders; adequate management of their expectations; appropriate management of the organization's objectives.

The development of the stakeholder's theory has focused on analyzing this through attempts to classify stakeholders into categories in order to help us understand how stakeholder groups can influence an organization. There is an agreement in the literature regarding the main stages in stakeholder analysis: identifying stakeholder groups (eg employees, owners, communities, customers, etc.), determining stakeholders' interest, and Assessing the type and level of stakeholder strength;

The result of stakeholder management is a strategy aimed at preventing, combating and resolving stakeholder issues.

In order for the stakeholder's theory to achieve its goals, it is necessary for the results to be quantifiable and to focus on prescribing how managers should administer the relationship with the stakeholders, explain what managers actually did in terms of relationships with them and predict what happens if managers respect the principles of the stakeholder's management.

Knowledge of primary and secondary priorities within stakeholder groups is necessary because the whole stakeholder theory is based on conceptual "stake" or "interest" (Freeman, 1984) - which best defines what motivates stakeholder groups.

We can conclude that the goal of stakeholder management is to facilitate the understanding of increasingly unpredictable external environments in order to increase the capacity to manage various situations within them. In terms of relations between stakeholders and their involvement in organizational management, most studies in the field focus on the relationship between the director as a stakeholder and other involved stakeholders, the key actor being the director (Mensch, 2011).

\section{The social, cultural and community responsibility of museums}

ICOM places the museum at the heart of society and its development. Changes in society have prompted museums to change, in line with changes in the needs of the communities they reflect and serve. 
The 2003 Convention on the Protection of the Intangible Cultural Heritage identifies three major stakeholder categories: community sources, government authorities (governing parties) and professionals. Identifying these three important stakeholder groups brings a different idea to the community and a whole set of beliefs about the importance and contribution of the cultural treasure of a community / country to social, cultural and political projects (Meijer-van Mensch, 2011).

PICBE $\mid 452$

Museums are forced to reflect more and more on mechanisms to ensure the recognition of a broad range of stakeholders.

A museum fulfills its duty to the benefit and trust of society, having a social responsibility in everything it does.

At the heart of the new ethical directions assumed by museums is the recognition of a wide diversity of stakeholders. The latest version of the 2004 Museums Code of Ethics for Museums recognizes the influence of various voices in the work of museums and in their interest. Article 6 of this Code is dedicated to the collaboration between museums and communities, while in 1986 the collaborations between both: museums on one side, and museums with local and governmental / central authorities were encouraged. The new Code calls for respect for the wishes of the community and the creation of a favorable framework for community support (Boylan and Woollard, 2006).

There are a multitude of stakeholders who have different interactions and interests with the museum. Any analysis should include the current interaction as well as the potential interaction with the stakeholders.

Many of the so-called good practices in the ethical conduct of organizations are the result of a stakeholder negotiation process.

The concept of social responsibility emerged in the 1960s, designating a company's initiatives to evaluate and take responsibility for its effects on the environment and social welfare, and the museum talks emerged in the early 1980s, and stressed that museums have the potential to contribute to tackling social inequality and the responsibility to do this (Sandell, 2007).

In Bach (2016), social responsibility is closely linked to authority - the way companies express their authority is by using their financial skills. Financial power cannot be taken into account regarding museums. In this case, the most prominent source of authority is the cultural one (this is based on their collections and the knowledge gathered around them). The social authority of museums is expressed by how they use their collections and knowledge in society, and how to make use of them is through exhibitions, conferences, publications and other media coverage.

The changing role of museums has been a key point in the museum's speech in the recent years, including in all strategic planning activities. The museums have become major players in social integration and local democratization (Mellemsether, 2016) and have placed greater emphasis on the involvement of visitors and public authorities to create a shared image of both: the city, and the community they belong to, appropriate to the present time (Varosio, 2006).

\section{Cultural sustainability of museums}

Museums are considered to be the keepers of cultural heritage, and therefore their role in preserving the tangible and intangible aspects of inheritance for future generations is generally not contested. 
The relations between museums, cultural sustainability and cultural policies as a model for the sustainable development of museums is well presented in a study conducted at the museums in Cyprus (Stylianou-Lamberta et al., 2014) where we can see that stakeholders can contribute to different aspects of cultural sustainability, and the examination of the main stakeholders (the state, the municipality / the community and individuals) leads us to the main forces that influence them, which are involved in organizing different types of museums and their effect on cultural sustainability: State Museums - memory, identity and politics; Municipal / Community / Citadine museums conservation and cultural tourism; Private Museums - various interests and programs.

Museums have become a key element in urban space due to their potential in generating local revenues, which leads to boosting city economies. The role of museums is all the more important as they support cities in their promotion as cultural centers on the domestic and foreign markets (visitors and investors), fulfilling their demands and expectations, becoming important vectors in the city development process. The impact of museum organizations is different from one city to another, from one country to another, at local, regional or national level (Popescu and Corbos, 2011).

All local museums address the local population but hope to attract tourists. Those in large cities are able to reach these goals much more easily than those in small towns. In local authority priorities, tourism and culture are important points and are usually in the same portfolio at municipal level - a beneficial thing because politics is decided by a single department (towards national authorities where culture and tourism are usually part of different portfolios).

In contemporary society, culture has become a product. Cultural tourism, as a type of tourism and type of business, is inevitably linked to profit. Cultural goods are expected to perform a wider range of cultural and tourist functions, and the role of museums evolves similarly, although studies may argue that goods such as museums are more than commercial goods, especially when tourism involves cultural heritage and it becomes a cultural product for consumers - visitors and the general public.

Perception of a product is closely related to its ability to meet needs and requirements. Therefore, for tourists, tourism products are experiences that have to meet the requirements and needs.

Museums are a stimulus for the development of urban tourism. The desire to visit a museum will make visitors to the museum, tourists for the cities in which it is located, and will offer the opportunity to visit other cultural locations. As a rule, museum visitors come from a higher social class with higher incomes, which leads to higher spending on stays spent here.

Museums can make symbols for their cities, their very relationship being a symbiotic one - museums offer the city cultural and economic life (creating new jobs and diminishing unemployment), and the city must offer them the opportunity to prosper (Popescu and Corbos, 2011).

Museum stakeholders are extremely important in the development of museums as tourist attractions. Cultural tourism has become a popular term in the field of tourism, when visiting the museum has become a major tourist activity. Traditional theories emphasize that the primary purposes of the museum are collection, exposure, research and education. Today traditional features are extended with features in tourism. 
The involvement of outsiders in the organizational activities of the museum is not new. Museums involve such people through various forms of dialogue from the very beginning of modern museums, especially in the field of collections management, where the activity of documenting and collecting objects and stories was done with the help of informers outside the museum through interviews, conversations or other personal communication forms. In this type of collaborations the decisive voice is always the museum, the role of "the other" being to help the specialized staff (Mellemsether and Muller, 2016).

Specialists and researchers describe the practice of engaging the public in different ways and words: commitment, involvement and participation are all concepts that describe a form of cooperation between museums and external groups. The methods often used are: dialogue, co-creation, and other forms of cooperation to achieve an objective.

"People outside the museum" are the museum's public. Participation and involvement of the public are key concepts of today's museum theory, but their integration into the everyday practice of museums proves to be still very difficult (Mellemsether and Muller, 2016).

The relationship of a museum with its audience is quite special. Visitors are coming to another universe where they have the opportunity to develop themselves, to recreate, to have fun, to perform activities that are totally different from the daily routine. Their life is altered by museum experiences, at least in those moments of direct interaction (Zbuchea and Ivan, 2008).

In turn, the museum depends on the public, having the mission to develop, preserve, study and conserve patrimonial possession for the benefit of its public, the community, and society. Without public the museum would be a lifeless organization.

The whole museum activity is a service for the society and requires the highest standards of professional practice. In order to be effective, the museum service has to gain the trust of the public it serves, an important role being played by initiatives to raise awareness of the museum`s role and management.

\section{Conclusions}

According to the above, we can say that museums, as cultural organizations, are a brick at the foundation of economic development in many cities. Even if the profit of museums cannot be seen directly in tax reports, they are a springboard for economic profit in other sectors.

The determining factors in the functioning of a museum are the environmental factors and the social background in which it is found. The museum must occupy a clear position in society, which makes the relationship between the institution and society essential.

The quality of the experience of each visitor must be a central concern of any museum. Many of the contemporary museums agree that they should focus more on the public than on the collection. Taking into consideration the fact that exhibitions and educational products are means of encouraging public involvement in the museum, the quality, security and preservation of collections must not be compromised. However, novelty remains the increasingly important role that a visitor can have in the team of a museum with a management appropriate to current requirements. 
Although the traditional purpose of museums is to educate, collect, conserve, and research, the museum's offer must be diversified in the context of a constantly changing society and with the new partnerships in the tourism and recreation industries. The museum`s economic role being increasingly more important, an emphasis on both: the museum's recreational function, and the necessity of innovation(in organization, management, and visitor experience) are required, in order to keep up with the changes.

PICBE | 455

The involvement and support of the stakeholders is essential for a museum that wants to set and meet appropriate community service goals. Understanding stakeholder`s value is important for effective reporting on the performance of the museum, which transforms and translates through continuous public support for the museum.

\section{References}

Association of Museums in the Netherlands (2010). Museum Management and Museum Education in Romania, Amsterdam.

Bach T. (2016). Reasons to involve the authority and social responsibility of museums. Open Patrimony Magazine. Changing Museums, Changing Communities, Changing Traditions, Publishing House „ASTRA Museum”, 75-96.

Bratianu, C. \& Bolisani, E. Knowledge strategy: An integrated approach for managing uncertainty. In Garlatti, A. \& Massaro, M. (Eds.). Proceedings of the $16^{\text {th }}$ Conference on Knowledge Management, University of Udine, Italy, 3-4 September 2015 (pp.169177). Reading: Academic Conferences and Publishing International.

Boylan, P., \& Woollard, V. (2006). Running a Museum: The Trainer's Manual: for Use with' Running a Museum: a Practical Handbook'. UNESCO.

Bucur, C. (2006). What it is, what can be, what must be a museum today. Museum Magazine, 1, 9-14.

Freeman, R. E. (1984). Strategic planning: A stakeholder approach. Pitman, Boston.

Gheorghiu, M. (2013). Museum, nation, history. Museum of the Romanian Peasant, the "place of memory" disputed. Retrirved from http:/www.academia.edu.

Lindqvist, K. (2012). Museum finances: Challenges beyond economic crises. Museum Management and Curatorship, 27(1), 1-15.

Meijer-van Mensch, L. (2011). New challenges, new priorities: analyzing ethical dilemmas from a stakeholder's perspective in the Netherlands. Museum Management and Curatorship, 26(2), 113-128.

Mellemsether, H. (2016). Experience from working in bilateral projects. Open Patrimony Magazine. Changing Museums, Changing Communities, Changing Traditions, Publishing House „ASTRA Museum”, 2016, 7-8.

Popescu, R. I., \& Corboş, R. A. (2011). Study on the sources of increasing the competitiveness of the national history museum of Romania in the context of urban development through the analysis of visitors' perception. Transylvanian Journal of Administrative Sciences, 29(2), 155-172.

Sandell, R. (2007). Museums and the Combating of Social Inequality: roles, responsibilities, resistance. Museums and their Communities, 95-113.

Stylianou-Lambert, T., Boukas, N., \& Christodoulou-Yerali, M. (2014). Museums and cultural sustainability: stakeholders, forces, and cultural policies. International Journal of Cultural Policy, 20(5), 566-587. 
Varosio, F. (2006). City museums: from urban institutions to a new concept of exposure and education. Museum Magazine, 1(03), 54-69.

Vicente, E., Camarero C. \& Garrido M. J. (2012) Insights into Innovation in European Museums, Public Management Review, 14(5), 649-679.

Wolfe, R. A., \& Putler, D. S. (2002). How tight are the ties that bind stakeholder groups? Organization Science, 13(1), 64-80.

PICBE | 456

Zbuchea A. (2010). The Museum 2.0, Marketing and Education in Museums (coord. Ovidiu Baron, Eliza Penciu), Sibiu: Astra Museum, 1(2010), 7-24.

Zbuchea, A. (2005). A marketing vision on museum exhibitions, Museum Magazine 1(2), 8185. 